\title{
A Unique Approach of Memory Narrative Therapy in Diasporic Contexts: An Analysis of The Bonesetter's Daughter and The Kitchen God's Wife by Amy Tan
}

\author{
Naeimeh Tabatabaei Lotfi \\ Department of English Language Translation, College of Humanities, Shahr-e-Qods Branch, Islamic Azad University, \\ Tehran, Iran
}

\begin{abstract}
Unlike the usual trauma situations, where narrative therapy could be utilized as a healing remedy, in diasporic context, the major errand of recalling memory for immigrants is constitution of a sense of 'self', that confirms with their national identity; and the chief mode of conveying this identity is via talk- stories. Although, recalled reminiscences are distorted and discontinuous but they facilitate the psychological redemption of afflicted trauma survivors. In the diasporic context, a distinctive stratagem is employed since there is not a will to talk with strangers in narrative therapy circles, by migrant trauma victims; this typical technique would secure a sense of national identity among migrants. This study is an investigation of a unique strategy of narrative therapy in diasporic context, in major novels of Amy Tan, as a second generation of Chinese migrants.
\end{abstract}

Index Terms-narrative therapy, trauma, memory narratives, Amy Tan, diaspora

\section{INTRODUCTION}

The haunting power of past memories, intensified in traumatic incidents, forces the individuals to create an eligible picture of past; this would ensure a secured sense of 'self'. The process of recalling memories of traumatic event challenges the validity of stored images. Basically, the mind, proficiently, distorts the past and the outcome is representation of erratic memory. Repudiating the legitimacy of the presented images of past means existence of fashioned memory, in which fact and fancy are amalgamated, to fabricate a holistic picture. However, for migrants, foundation of a sense of 'self' is allied with national identity; usually, it is created by oral histories about past, in the form of memory narratives. Memory narratives could be considered the psychological solutions, to heal the victims of traumatic past incidents. Narrative therapy could be an inseparable part of memory narratives, in which recalling is the main narrative strategy to cure the past. But there is not a will to participate in therapy sessions by most of migrant communities; they usually prefer to share their trauma stories with their families or their close friends. They believe that sharing suffering with others would be a source of humiliation for them and their nation. Especially, migrant women, afflicted by suppressive forces inside their family as well as outside, are unwilling to share their narratives in therapy sessions. Their actions are always mixed with silence. Their retrospective accounts are marked by a sudden comprehension of the cruel passage of time that bestows them with courage, to share their memories with their children who are indifferent to these narrative, most of the times. As many cases of close reading of literary texts, this study is designed to interpret the disparate manifestations of memory's representation in characters' narratives and the way it influences their life and the life of people around them. Characters' desires and fears possibly will be recognized by scrutinizing their memory narratives. The literary texts provide clues to find the roots of character's actions and their present subjectivity. This study is an attempt to scrutinize a unique strategy of narrative therapy applied in diasporic contexts in major novels of Amy Tan. The Bonesetter's Daughter (2001) and The Kitchen God's Wife (1991) are two novels which are under the examination, in this research.

\section{THEORIZING NARRATIVE THERAPY}

The oral reproduction of memory narratives has long proved to heal past, empirically. The comfort and the ease felt after sharing traumatic memories with others is a substantial reality. This established a scientific research to explore the mechanism and the impact of recalling within groups. The term 'narrative therapy' was coined by Michael White, David Epston, and many other psychologists. Narrative therapy concentrates, mainly, on the function of narratives in the process of healing mental injuries, by generating a vivid picture of life events. It involves an act of deconstructing the current, established meanings of actions, through questioning the long held assumptions. This would provide multiple possibilities for appreciating one's life. Narrative therapy assumes that identities are chiefly constituted by stories of life, whether personal or social. Like postmodern movement, it highlights the narratives of marginalized 
discourses, in contrast to hegemonic social practices. This process is achieved through objectifying and externalizing the problems; it involves a re-evaluation of hegemonic values. In sessions of narrative therapy people are allowed to express their versions of experiences and this leads to constitution of a fruitful interpretive act that assigns a certified meaning to past events. Production of different versions of narratives is a cultural process and it is governed by cultural context of the individuals who express them; and like every other cultural matters, these narratives are not static, but they are open to modification. The main goal of narrative therapy is determined by the amount of knowledge and intelligibility that it provides the individuals with; it may change their perspectives in life, forever. By meeting other possible alternatives in life, people discover novel skills and capacity within, that all comes from past experiences.

Tabatabaei Lotfi (2014) suggests that,

Nevertheless, there must be a 'will' behind sharing memories. In most cases, especially in the cases of sexual and racial abuses and domestic violence, victims are unwilling to talk about their suffering; this might be because of the fear of later troubles by oppressors or social stigmatization. For migrant communities, this is doubled by cultural impediments; there could be also language barriers that add to the complexity of communicating. Unfortunately, most of these trauma stories are unnoticed or ignored by psychologists and society, but there are some movements to hear and cure the pain of past. (p.143)

Unfortunately, in diasporic contexts, in which there are multi- factorial suppressive elements, migrants prefer to keep silent about their traumatic experiences. Gradually, this silence is shattered by migrants who start to talk about their traumas, within narrative therapy circles. There has been a movement by migrant writers to inform people about the stories of their diasporic communities.

In a collaborative paper published by "The International Journal of Narrative Therapy and Community Work", a collection of different therapists' theories, on the latest accomplishments of this field by David Denborough (2004) is put forward. Additionally, the necessity of a reciprocal method for a better mutual comprehension of trauma narratives is suggested. Shona Russell believes that, recently, the position of the therapist as the holder of skill and knowledge has dramatically changed to a person who asks questions to explore different perspectives of people's life, through their narratives. However, the acquired knowledge may well be shared by other practitioners and patients (p. 30). Russell points to the inspiring act of sharing experiences with others in therapy sessions, "It also evokes a sense of joint exploration. Together we are setting out to explore territory that hasn't been explored before. Together we are trying to seek out unique outcomes and ways of re-authoring these into preferred storylines" (p. 32). The search for invisible consequences of past in one's life illuminates that there are many unexplored meanings to it; the act of meaning making is an impartial endeavor to discover truth, because narratives are interpreted multi-dimensionally. The produced data is, then, employed to provide justice for others. Sadly, some of these stories are shocking and immobilizing and leave a permanent impression of rage and anger in therapist that would affect the progression of narrative therapy.

\section{Migratory NARRATIVES}

Migration literature is a field of innovatory techniques of narration. Evidently, the major aim of sharing memories is uniting the immigrant families, as well as helping parents to transmit their national identity to their children. The significant point is that, in the course of recalling memory, a collective identity is constructed, as well as the individual identity. Like many other discursive social disciplines that interact perpetually in constructions and deconstruction of each other, the modes and patterns of recalling in a certified historical context, would produce diverse, yet communal products; these are manifested in the form of national myths and legends of a particular nation.

The narratives that individuals create as their individual memories might not be their own experiences of the incidents, entirely, since the formation of identity is in closely linked to the "autobiographical memory" and grants a "sense of personal continuity and consistency over historical time that forms the backgrounds for individual's interaction with others and serves as a reference point for self-reflective activities" (Waites, 1993, p. 14). It implies that in order to make sense out of incidents, the individuals locate themselves in accordance with memory; recalling traumatic events is in the form of the recollection of memories in an active process to satisfy a mutual desire. In diasporic context, a sense of autonomy prevails that is originated in the geographical dislocation; this would assist the process of disregarding, as well as the procedure of recollecting. Both of these activities are exposed to fictionalization. Therefore, an imaginary version of past is represented by migrant communities, which tries to cover the bitter parts of recalled memories.

In the strife to constitution an integrated 'self', a linear chronological order must be generated; in the cases of different types of Dementias, the loss of memory would result in social withdrawal. In migrant societies, this memory loss is a moral sin, a national crime or loss of a nation's memorial heritage.

Unfortunately, in diasporic contexts, children's estrangement with their inherited culture heaps on the sense of isolation. Additionally, the malfunction of communicating with the host culture incarcerates the practice of storytelling to domestic spheres. Thus, the issue of narrative therapy that could be an inseparable part of memory narratives appears to be an inconvenient subject in the context of migration, because most of migrants are reluctant to go through sessions of consulting; they are distrustful toward consulting institutes which are representative of the dominant, hostile host culture. Apparently, the concept of narrative therapy is excluded in migratory narratives, because, it is a voluntary participation, in consulting sessions by individuals. 
The practice of recalling past by migrant writers is not a new notion, according to Carol Boyce Davis (1998). Recalling memory is transgression of borders of time, history and space. The policy of memory becomes the main concept in construction of past, in a new and logical present that has the function of articulation of meaning and creating coherence. The function of memory, in breaking the conventional norms of narration and violating the laws of time and history, creates a rich blend of impeccable version of stories which usually belong to migration narratives (p. 1006). In diasporic context, immigrants are free from their previous confinements; this leads to creativity and novelty, in their narratives; thus it would have a healing effect on them. However, the fallacious nature of memory generates distorted images of past by migrant communities.

\section{A. Story Telling Policy by Amy Tan}

There are resemblances between Amy Tan's personal life and the lives that she pictures, in her narratives; for instance, allusions to her grandmother's suicide are traceable in The Kitchen God's Wife and The Bonesetter's Daughter. Her mother's difficult life in a foreign country is also depicted in various texts. Sharing memory, in the form of storytelling, is not only the raw material for Tan's novels, but also fashions a fertile field, for formulation of identity. Through memories of mothers, the American born children gain an imagined Chinese identity; frequently, it is in conflict with their American ones. Mothers of Tan's novels, as well as her own mother, are all among the first generation of immigrants from China, who speak very little English and feel culturally alienated in their new context. Nonetheless, sharing memories within the domestic domains of diasporic families is a redemptive act which guarantees the mental and psychological integrity of characters.

The daughters, mentioned in the novels, are all born and educated in America; Ben Xu (1994) suggests that, "within the microcultural structure of family, the only means available for mothers to ensure ethnic continuity is to recollect the past and to tell tales of what is remembered" (p. 2). He believes that in dealing with memory narrative, it must be considered that each narrative may contain a double layer, one related to "life-story" and the other related to "existential perception" that it entails. "If the life-story is marked by a seeming actuality, existential perception is what transforms the casual daily events into a functioning mentality or an existential concern that is not self-evident" (p. 4). This means that in narrating memories of past, not only the actual events are remembered, but also the external reality of the present is attached to them that makes them convincible, in the present condition. "Memory narrative does not represent a perfect equivalent of the events it purports to describe. It goes beyond the actuality of events to the determination of their coherency as an existential situation, and this general picture of life in turn assigns exemplary values to the events which are awakened in memory by a functioning mentality"(p. 4). This quotation expresses the value of the discourse of memory in social significations. Incidents are interpreted with a retrospective function of memory narratives; the decisions are also made, regarding the present perception of past.

By storytelling, Chinese parents transmit their familial history to the next generation. Therefore, the younger generations obtain some sense of sympathy toward their ancestors and dreams that were to be fulfilled in The United States. American-born children, ostensibly, are liberated from their parents' past. Still, they are obsessed dramatically about their ancestral land. They are haunted by past, and the mystery associated with it; a mysterious past that existed only in the memories of their parents. Intelligently, Tan has used this strategy to narrate her stories. All of Tan's novels have parallel narratives, one related to the past which is retold by mothers, and in one case a step sister who has come back from China; and the other is associated with the present stories of daughters about the cultural conflicts and alienation, they feel regarding the ancestral heritage of their home which has been transmitted to them by means of past memories. The point is that storytelling plays an essential position in creation of a new, more Chinese identity, in contrast to the previous American one, McDaniels (2004) states that,

Basically, both versions of the stories, mother's and daughter's are necessary for revealing the complete story, including the painful secrets, whether the pain is alleviated or just changes its context. Both mothers and daughters need to tell their versions and listen to the others' versions in order to have all the information necessary to arrange their own stories in complete form. Women (in these texts and in general) need each other in order to know themselves completely. (p. 128)

Hence, storytelling is the only possible means of communication for alienated mothers and daughters. In this process, memory converts into an instrument of representing past images of China. Surprisingly, in the exchange of secrets, located at the end of the novels, characters obtain an impeccable insight about themselves and their Chinese identity. Sharing memories, in the form of oral histories, has been always considered a feminine act of breaking the silence and marginalization. The structure of the narratives demonstrates the individual tragedies of mothers' life in China, as well as, the obscurities of cultural transformation. The act of storytelling accentuates the mothers' strength in China where they were suggested to be invisible and voiceless human beings. They tell their stories to preserve their ancestral history, in addition to emphasizing their cultural differences. However, they find themselves muted in America, because their English is not good enough and they feel culturally alienated.

Cynthia Wong (1997) studies the process of narration, in novels of Amy Tan in her article, "Asymmetries: Loss and Forgiveness in the Novels of Amy Tan". She suggests that recalling past memories and their narrative exhibition is a kind of defense mechanism to guarantee the integration of 'self' in the context of America,

Subsequently, their survival in the new context depends upon a reliable mechanism for expressing what really happened. However, elusiveness of such a mechanism is evident as the mother's narratives progress, and therein lays 
the incongruence of understanding between mothers and daughters. In expressing the twists and turns of experiences and their own altering responses to experiences past and present, Tan's characters frequently shift their own subjective, or narrating, positions. (p. 64)

The permanent changes of characters' stories would lay emphasis on the dynamicity of memory that provides a safe personal access to past. This designs a fictional realm out of the seemingly factual stories of mothers. Amazingly, the reconstruction of the mother's narratives is a cultural response to the wide detachment that they feel among themselves and their daughters. Fallacious nature of memory ensures family's union and provides mothers with a solution to their everyday problems, in diasporic context. Wong, then, concludes that, "storytelling in Tan's fiction is involved with the persistent shifting and reshaping of myths that have healed and comforted these women devastated by the magnitude of their losses. Tan imagines and constructs their efforts at forgiveness by renouncing their ability to unify the disparate experiences of women and their progeny originating from China" (p. 75). Recalling memories promises a better future for alienated mothers; their narratives are feministic endeavors to save their national, communal identities.

\section{B. Act of Narration in Tan's Novels}

The Bonesetter's Daughter narrates mother-daughter conflicts in an Asian- American family, where the mother's past is the key to healing mental injuries of the present. The story initiates, quickly, with the introduction of major character of the novel. The major character of the novel is Ruth Yang, a Chinese- American who is a ghostwriter; she undergoes a short enigmatic annual muteness. Besides, her life is under great pressures with factors such as clients, her husband Art and two step-daughters and most of all, incapability to create a mutual empathy with her mother, LuLing, who forces her to communicate with the ghost of her dead grandmother. Then, the story promptly, moves to the main narrative which is description of Ruth Young's life in America. In the middle of the story, LuLing's manuscript is found and this disrupts the ordinary current of life for Ruth; it is about past, when LuLing was still in China. Through reading LuLing's manuscript, about her memories in China, Ruth comes to get a new perception toward her life and tries to solve the struggles between her mother and herself. She starts to amend her life by initiating a unique creative writing, with all immaculate insight that she has attained about herself. In other words, by looking back and by the power of recalling past memories, Ruth has obtained a new vision of future; as she writes the story of her mother and her grandmother, she reveals her vision, in the closing words of the novel,

They write about what happened, why it happened, how they can make other things happen. They write stories of things that are but should not have been. They write about what could have been, what still might be. They write of a past that can be changed. After all, Bao Bomu says: 'what the past is but what we choose to remember? They can choose not to hide it, to take what's broken, to feel the pain and know that it will heal. They know where happiness lies, not in a cave or a country, but in love and the freedom to give and take what has been there all along. Ruth remembers this as she writes a story. It is for her grandmother, for herself, for the little girl who became her mother. (p. 197)

The identity conflicts are not restricted to LuLing and her mother, as Chinese, but they are also applicable to Ruth who has been born in America and thinks of herself as an American. Ruth is troubled, embarrassed and humiliated by her mother's Chinese behavior and criticizes her for her inability to assimilate with the American culture, "her mother couldn't even say Ruth's name right. It used to mortify Ruth when she shouted for her up and down the block. 'Lootie! Lootie!' Why had her mother chosen a name with sounds she couldn't pronounce?'(p. 24). Her embarrassment is intensified as she is considered the same as her mother, by others; they identify her with LuLing, except in the case that she can speak English. She has to be "LuLing's mouthpiece" and become "English-speaking 'Mrs. LuLing Young' on the telephone" (p. 24). This would clearly indicate the ambiguous state of migrant children. No matter how hard they strive, they are attached to their national culture, with an invisible thread; this magnifies their confusion.

Ron Eyerman (2004) suggests that memory is the product of "symbolic interactions, narrative and discourse"; and this means that it might be documented in a written form, as well as oral form (p. 162). By hiring someone to translate the mother's manuscript and discovering the real name of the grandmother, the novel moves toward a shared communication, which is based on the construction of a joint identity, "Precious Auntie belonged to a family. LuLing belonged to that same family, and Ruth belonged to them both. The family name had been there all along, like a bone stuck in the crevices of a gorge" (p. 196). Little by Little, Ruth respects her ancestral legacy that is supposed to be transmitted to her by the means of mothers and their stories of past; and it is the beginning of a sense of belonging to China as homeland,

As Ruth now stares at the photo, she thinks about her mother as a little girl, about her grandmother as a young woman. These are the women who shaped her life, who are in her bones. They caused her to question whether the order and disorder of her life were due to fate or luck, self-determination or the actions of others. They taught her to worry. But she has also learned that these warnings were passed down, not simply to scare her, but to force her to avoid their footsteps, to hope for something better. They wanted her to get rid of the curses. (p. 196)

Here, past becomes the source of redemption and mutual perception for members of a migrant family, which was threatened to shatter. Ruth discovers the answer to her philosophical questions about life. Interestingly, this insight belongs to a feminine sphere and its instructors are all women who share their memories with their daughters, to protect them from hazards of life. Unlike Tan's other novels, which are based on oral narratives of mothers, this story develops by the act of documenting past. However, the written word serves to perform as the savior of ancestral memories and preserves the history of a family and in larger scale, a nation. 
The Kitchen God's Wife also profits the instrument of storytelling. Winnie and Helen are old friends and have kept each other's secrets about their past lives in China; they decide that it is the right time to disclose secrets about past, secrets so horrible that even, Helen, as a close friend is unaware of them. Again, there is a parallel mother/daughter narrative, in which it is the narrative of the mother that reshapes and reveals the real identity of the daughter. The major Character of the story, Pearl, understands that her mother, courageously, fought her difficult and tragic marriage to an abusive husband in China and came to America for a better life, while pregnant by him, as he maliciously raped him. The story ends with a return to China to cure the illness of the daughter, as a symbolic jubilation of return to national origin. The Kitchen God's Wife, also ends with a return to China in order to bring Chinese's medicine to cure Pearl; China again becomes equivalent to a remedy, for not only mental disease and unease of the characters, but also a remedy for their physical illnesses as Helen declares, "Chinese medicine can cure everything" and this includes a cure for identity imbalance of Pearl too (p. 406). According to Yuan, the novel is based on traumatic memories of homeland, "the China narrative is based on Winnie's painful experiences in China. In fact, the pain and suffering that are central to Winnie's recollection invite repression rather than recall. Her China narrative is subject to constant postponement and erasure to conceal the unspeakable experience and repressed memory" (p. 144). Nevertheless, the silence must be broken and memories must be recalled, because Pearl's mother thinks that the source of her illness is originated in her past. Helen mentions the unease felt by Pearl's mother in believing that she is the one who has given the disease to her daughter, "she thinks that she gave you your sickness" and also believes that her disease is "from an imbalance in nature"; and because she has her roots in China, the imbalance could only be cured there (p. 408). The source of disease is 'past' and the remedy is also in union with it; the voyage to China is compared to tasting magical water that might heal, not only physically but it can create a peace of mind by its strange effect on the memory of the past too, "I can taste it too. I can feel it. Only a little amount and it is enough to remember- all the things you thought you had forgotten but were never forgotten, all the hopes that can still be found" (p. 410). The omnipresence of past, in the form of memory, is the real reason for its diverse performance in the life of characters. It may cure and poison.

Walter Ong (1982) states that, "When a speaker is addressing an audience, the members of the audience normally become a unity, with themselves and with the speaker" (p. 74). Therefore, since the power of storytelling and sharing past memories lies in its capability to unite the minds of the speaker with those of the listeners, storytelling can diminish the communication and cultural obstacles which separated Chinese born parents and their American born children; it can fortify the bonds between parents and children. Additionally, it may have a curative effect on migrants who are unwilling to share their traumatic experience with strangers. It is clearly indicated that in diasporic contexts, the role of sharing memories within domestic domains is an outstanding one; this is also different with the usual narrative therapy sessions, for treating mental problems.

Accordingly, in Tan's novels, the remedial impact of sharing memories within diasporic communities would not only redeem the mental injuries of migrant society, but it also articulates a communal identity among them. This identity facilitates the act of communication among different generations of migrants, in a unique pattern. The memory narrative therapy is specified to migrant communities who refuse to share their traumatic experiences in therapeutic sessions.

\section{CONCLUSION}

Narrative therapy is a psychological cure in traumatic incidents. However, in diasporic contexts, a distinct tactic is used in sharing traumatic reminiscences. Usually, the migratory subjects are unwilling to share their memories with strangers in diasporic contexts and prefer to share it with their children in domestic spheres of their home. This would guarantee the transference of their national heritage to next generation and constitute a communal national identity among their diasporic communities. Memory narratives provide a fertile ground for a mutual dialogue among different generations; as if it is only through storytelling that the private monologue of memory is converted into a public meaningful dialogue and the lost sense of identity is regained among migrant communities. This study is an investigation of a unique strategy of memory narrative therapy, in diasporic context, in Amy Tan's The Kitchen God's Wife and The Bonesetter's Daughter.

\section{REFERENCES}

[1] Davis, Carol Boyce. (1998). Migratory Subjectiveness. In J. Rivkin, M. Ryan (Eds.), Literary Theory: an Anthology. pp 9961015. Malden: Blackwell.

[2] Denborough, David. (2004). Narrative Therapy and Research. The International Journal of Narrative Therapy and Community Work 2. 29-36.

[3] Eyerman, Ron. (2004). The Past in the Present: Culture and the Transmission of Memory. Acta Sociologica, 47.2. 159-169.

[4] Mc Daniels, Preselfannie W. (2004). Mothering Modes: Analyzing Mother Roles in Novels by Twentieth Century United States Women Writers. Ph.D. dissertation, Louisiana State University and Agricultural and Mechanical College.

[5] Ong, Walter J. (1982). Orality and Literacy: The Technologizing of the Word. London: Routlegdge.

[6] Tabatabaei Lotfi, Naeimeh. (2014). Scrutinizing the Discursive Nature of 'Memory' in Amy Tan's The Kitchen God's Wife \& Ian McEwan's The Child in Time. International Journal of Applied Linguistics \& English Literature. doi:10.7575/aiac.ijalel.v.3n.3p.141-150.

[7] Tan, Amy. (1991). The Kitchen God's Wife. New York: Penguin Group.

[8] Tan, Amy. (2001). The Bonesetters' Daughter. Reader Works TMPublisher, Over Drive, Inc. www.readerworks.com. 
[9] Waites, E. (1993). Trauma and Survival: Post Traumatic and Dissociative Disorders in Women. New York, US: WW Norton \& Co.

[10] Wong, Sau-ling Cynthia. (1997). Chinese American Literature. In K.K, Cheung (ed.), An Interethnic Companion to Asian American Literature. New York: Cambridge UP, 39-62.

[11] Xu, Ben. (1994).Memory and the Ethnic Self: Reading Amy Tan’s The Joy Luck Club. MELUS 19.1, 3-19.

Naeimeh Tabatabaei Lotfi has a PhD in English literature from Islamic Azad University, Tehran Central Branch. She is a member of faculty in Department of Translation of English Language in Islamic Azad University, Shahr-e- Qods Branch. At the time, she is a lecturer and supervisor in M.A courses. Additionally, she is interested and researching in Teaching and Translation studies as well as Literature. 